\title{
Mitral valve replacement with maintenance of mitral annulopapillary muscle continuity in patients with mitral stenosis
}

Postoperative left ventricular performance was evaluated in patients with mitral stenosis who underwent mitral valve replacement with maintenance of the continuity of the mitral anulus and papillary muscles. Mitral valve replacement with preservation of autologous chordae tendineae $(n=7)$ or their replacement with expanded polytetrafluoroethylene sutures $(n=14)$ was performed in 21 patients with mitral stenosis. Hemodynamic parameters were compared with those of 28 patients who underwent conventional mitral valve replacement and 27 patients who underwent open mitral valve commissurotomy. No deaths occurred in the early or late follow-up period. All hemodynamic parameters were improved after the operation, and no significant differences were detected among the three groups with regard to postoperative cardiac index or mitral valve area. No significant differences were observed in left ventricular end-diastolic volume index, end-systolic volume index, or contractility index, but the postoperative left ventricular ejection fraction in the chordal preservation and open commissurotomy groups was greater than that in the group having conventional mitral valve replacement. Postoperative regional shortening was greatest at the diaphragmatic portion in the chordal preservation group and at the long axis in the open commissurotomy group. In the mid-term postoperative period, although no differences were noted among the three groups in echocardiographic data or global ejection fraction measured by multigated equilibrium radionuclide angiography, the regional shortening at the anterolateral portion of the left ventricle in the chordal preservation and commissurotomy groups was greater than that in the group having conventional mitral valve replacement. Postoperative radionuclide angiography during exercise failed to demonstrate any difference between the ejection fraction in the chordal preservation group and that in the group having conventional mitral valve replacement. (J THORAC CardiovasC Surg 1994;108:42-51)

Yutaka Okita, MD* (by invitation), Shigehito Miki, MD (by invitation), Yuichi Ueda, MD (by invitation), Takafumi Tahata, MD (by invitation), Tetsuro Sakai, MD (by invitation), and Katsuhiko Matsuyama, MD (by invitation), Nara, Japan

Sponsored by Tadaomi Miyamoto, MD, Kitakyushu, Japan

P and the papillary muscles results in improved postopera-

From the Department of Cardiovascular Surgery. Tenri Hospital, Nara, Japan.

Read at the Seventy-third Annual Meeting of The American Association for Thoracic Surgery, Chicago, Ill., April 25-28, 1993.

Address for reprints: Yutaka Okita, MD, Department of Cardiovascular Surgery, National Cardiovascular Center, Fujishirodai 5-7-1, Suita, Osaka, Japan 565.

*Present address: Department of Cardiovascular Surgery, National Cardiovascular Center, Osaka, Japan.

Cópyright $\odot 1994$ by Mosby-Year Book, Inc.

$0022-5223 / 94 \$ 3.00+0 \quad \mathbf{1 2 / 6 / 5 4 5 9 5}$ tive systolic left ventricular (LV) performance after mitral valve replacement (MVR) in patients with mitral regurgitation. ${ }^{1-3}$ However, few investigations ${ }^{4}$ have been conducted in patients with mitral stenosis in which the stiff subvalvular complex is preserved or replaced to improve postoperative $\mathrm{LV}$ performance or prevent posterior midventricular disruption after MVR. David ${ }^{4}$ first reported the technique of reconstructing synthetic chordae after excision of the mitral apparatus. In this study, the $L V$ performance in patients with mitral stenosis who underwent MVR with either preservation of all chordae tendineae or replacement of chordae with expanded polytetrafluoroethylene (e-PTFE) sutures was compared 
with that in patients who underwent conventional MVR or open mitral valve commissurotomy (OMC). LV performance was evaluated in the early postoperative period by means of cineangiography and in the mid- to long-term period by means of echocardiography or multigated equilibrium radionuclide angiography (MUGA).

\section{Patients and methods}

Between February 1984 and March 1994, 37 patients with mitral valve disease underwent MVR with preservation of all autologous chordae tendineae or, in 22, MVR with chordal replacement with e-PTFE sutures. Twenty-one patients with mitral stenosis without significant mitral regurgitation, other valvular lesions, or coronary artery disease were selected for the present analysis. They included five men and 16 women whose ages ranged from 30 to 74 years (mean 52.6 years). The valve disease was solely of rheumatic origin. Eighteen patients had atrial fibrillation. The LV performance in these patients was compared with that in 28 patients who underwent conventional MVR and 27 patients who underwent OMC for isolated mitral stenosis during the same period. No significant differences were observed among the three groups in gender, age, or the severity or cause of mitral valve disease. The methods of anesthesia, cardiopulmonary bypass, and myocardial protection were also similar in all patients.

$\mathrm{We}^{5}$ have previously described the technique for preservation of all the chordae tendineae during MVR. Our technique for replacement of the chordae tendineae is as follows ${ }^{6}$ (Fig. 1): After it is determined that the rheumatic lesions of the subvalvular apparatus are too severe for repair, the anterior mitral leaflet is resected, and the fused chordae are transected at their insertion into both papillary muscles. The posterior leaflet is resected as well, except for the basal chordae. The continuity between the papillary muscle and mitral anulus is restored with four e-PTFE mattress sutures.* The mattress stitches with autologous pericardial pledgets, preferably vertical, are placed at the compact portion of the papillary muscle and tied down over a small piece of autologous pericardium. After the desired length is measured, markings are made on the sutures with violet ink. The suture is placed at the mitral anulus over a small piece of autologous pericardium and is tied down at the markings, held by a right-angled clamp applied to the pericardial buttress. Four e-PTFE mattress sutures are then placed, tied onto each papillary muscle, and then sutured and tied down at the $2,4,8$, and 10 o'clock positions on the anulus. The mitral valve is replaced with a low-profile bileaflet mechanical prosthesis (St. Jude Medical, Inc., St. Paul, Minn.) with horizontal mattress stitches of 2-0 polyester (Ethibond; Ethicon, Inc., Somerville, N.J.). The motion of the prosthetic leaflets is carefully examined to prevent leaflet entrapment by the artificial chordae. The LV outflow tract is also carefully examined to exclude any potential induction of stenosis by the artificial chordae tendineae.

We determined the length of the artificial chordae according to the size of the LV or disease of the papillary muscles with reference to the average distance from the tips of the papillary muscles to the mitral anulus as measured on 70 normal autopsy specimens from Japanese patients without cardiac disease. The

*Gore-Tex suture CV3, registered trademark of W.L. Gore \& Associates, Inc., Elkton, Md.

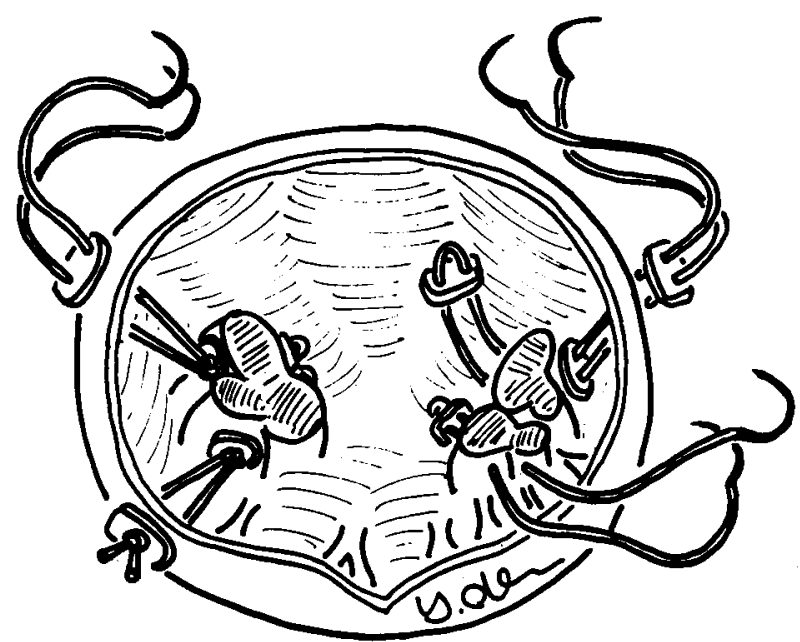

Fig. 1. Replacement of chordae with e-PTFE sutures. Thickened and deformed anterior and posterior mitral leaflets were resected, and the fused chordae were transected at their insertion into both papillary muscles, except for the basal chordae of the posterior leaflet. Four e-PTFE mattress sutures with autologous pericardial pledgets were placed on the anterolateral or posteromedial papillary muscle and tied down over a small piece of autologous pericardium. After a desired length of the suture was measured, the sutures were placed at the $2,4,8,10$ o'clock positions of the mitral anulus. A bileaflet prosthesis (St. Jude Medical valve) was inserted.

replaced chordae should be tight enough to generate some tension but should not be too short. The average distance from the papillary muscle tips to the mitral anulus of the normal heart at autopsy was $23 \pm 3.8 \mathrm{~mm}$ at the 2 o'clock position, $23.2 \pm 4.1$ $\mathrm{mm}$ at 4 o'clock, $22.7 \pm 3.5 \mathrm{~mm}$ at 8 o'clock, and $23.7 \pm 3.9$ $\mathrm{mm}$ at the $10 \mathrm{o}$ 'clock position. The length of this distance at autopsy in all cardiac specimens was similar regardless of the position of the mitral anulus. The mean length of the implanted artificial chordae tendineae was $22.0 \mathrm{~mm}$ (range from 15 to 25 $\mathrm{mm}$ ) at the 2 o'clock position on the mitral anulus, $22.0 \mathrm{~mm}$ (range from 15 to $25 \mathrm{~mm}$ ) at 4 o'clock, $19.7 \mathrm{~mm}$ (range from 15 to $25 \mathrm{~mm}$ ) at 8 o'clock, and $22.9 \mathrm{~mm}$ (range from 20 to 30 $\mathrm{mm})$ at the 10 o'clock position.

Among the 28 patients who underwent conventional MVR, a bileaflet prosthetic valve (St. Jude Medical) was inserted in 16 and a tilting-disc prosthetic valve (Björk-Shiley in 3 [Shiley, Inc., Irvine, Calif.] and Omniscience in 9 [Medical Inc., Inver Grove Heights, Minn.]) was inserted in 12. In the OMC group, conventional mitral commissurotomy was performed and fused chordae and papillary muscles were divided if necessary.

The mean interval from operation to postoperative cardiac catheterization was 29.5 days, ranging from 24 to 98 days. Cardiac output was determined by the Fick method. Preoperative and postoperative retrograde left ventriculography was performed by means of $35 \mathrm{~mm}$ cineangiography with the patient in the standard 30-degree right anterior oblique position. LV pressures were obtained with standard fluid-filled catheters. The LV volume was calculated by the area-length method and divided by body surface area to give a volume index. Pressure 
Table I. Cardiac catheterization in the preoperative and early postoperative periods

\begin{tabular}{|c|c|c|c|}
\hline & $\begin{array}{c}\text { Chordal preservation } \\
M V R(\mathrm{n}=21)\end{array}$ & $\begin{array}{c}\text { Conventional } M V R \\
(\mathrm{n}=28)\end{array}$ & $O M C(\mathrm{n}=27)$ \\
\hline \multicolumn{4}{|c|}{$\mathrm{CI}(\mathrm{L} / \mathrm{min}$ per square meter $)$} \\
\hline Preop. & $2.56 \pm 0.63$ & $2.54 \pm 0.62$ & $3.03 \pm 0.81^{*}$ \\
\hline Postop. & $2.99 \pm 0.41 \dagger$ & $3.05 \pm 0.54 \dagger$ & $3.21 \pm 0.70$ \\
\hline \multicolumn{4}{|c|}{$\mathrm{PCW}(\mathrm{mmHg})$} \\
\hline Preop. & $15.5 \pm 5.4$ & $19.0 \pm 7.8^{*}$ & $15.9 \pm 5.1$ \\
\hline Postop. & $9.3 \pm 3.1 \ddagger$ & $11.5 \pm 3.6 \ddagger$ & $11.5 \pm 3.5 \dagger$ \\
\hline \multicolumn{4}{|l|}{$\operatorname{MVA}\left(\mathrm{cm}^{2}\right)$} \\
\hline Preop. & $0.98 \pm 0.26$ & $0.94 \pm 0.27$ & $1.30 \pm 0.33^{*}$ \\
\hline Postop. & $2.06 \pm 0.82 \ddagger$ & $1.87 \pm 0.59 \ddagger$ & $1.90 \pm 0.52 \dagger$ \\
\hline \multicolumn{4}{|c|}{$\operatorname{EDVI}\left(\mathrm{ml} / \mathrm{m}^{2}\right)$} \\
\hline Preop. & $79 \pm 24$ & $85 \pm 28$ & $78 \pm 18$ \\
\hline Postop. & $90 \pm 26$ & $83 \pm 21$ & $75 \pm 16$ \\
\hline \multicolumn{4}{|c|}{$\operatorname{ESVI}\left(\mathrm{ml} / \mathrm{m}^{2}\right)$} \\
\hline Preop. & $41 \pm 15$ & $42 \pm 16$ & $39 \pm 13$ \\
\hline Postop. & $40 \pm 15$ & $39 \pm 14$ & $33 \pm 8$ \\
\hline \multicolumn{4}{|c|}{ EF (cineangiography) } \\
\hline Preop. & $0.49 \pm 0.13$ & $0.52 \pm 0.08$ & $0.50 \pm 0.06$ \\
\hline Postop. & $0.56 \pm 0.10^{*}$ & $0.49 \pm 0.09$ & $0.54 \pm 0.08^{*}$ \\
\hline \multicolumn{4}{|c|}{ Regional shortenings (centerline method) } \\
\hline \multicolumn{4}{|c|}{ Anterolateral portion } \\
\hline Preop. & $3.4 \pm 1.4$ & $4.0 \pm 1.3$ & $3.7 \pm 1.4$ \\
\hline Postop. & $4.3 \pm 1.6$ & $3.6 \pm 11.5$ & $4.0 \pm 1.5$ \\
\hline \multicolumn{4}{|c|}{ Anterobasal portion } \\
\hline Preop. & $1.5 \pm 0.8$ & $2.1 \pm 1.4$ & $1.7 \pm 0.9$ \\
\hline Postop. & $2.7 \pm 1.6 \dagger$ & $2.1 \pm 0.8$ & $2.6 \pm 1.0^{\dagger}$ \\
\hline \multicolumn{4}{|c|}{ Apical portion } \\
\hline Preop. & $2.0 \pm 0.3$ & $2.4 \pm 1.2$ & $2.3 \pm 1.6$ \\
\hline Postop. & $2.7 \pm 1.1$ & $2.4 \pm 1.0$ & $2.7 \pm 1.3$ \\
\hline \multicolumn{4}{|c|}{ Diaphragmatic portion } \\
\hline Preop. & $2.6 \pm 1.0$ & $3.2 \pm 1.3$ & $2.9 \pm 1.3$ \\
\hline Postop. & $3.7 \pm 1.6^{* \dagger}$ & $2.6 \pm 1.3$ & $3.2 \pm 1.5$ \\
\hline \multicolumn{4}{|c|}{ Posterobasal portion } \\
\hline Preop. & $1.6 \pm 0.7$ & $2.0 \pm 0.2$ & $2.2 \pm 1.0$ \\
\hline Postop. & $2.1 \pm 1.1$ & $1.6 \pm 1.0$ & $2.3 \pm 1.1$ \\
\hline \multicolumn{4}{|l|}{ Long-axis } \\
\hline Preop. & $1.9 \pm 7.3$ & $14.7 \pm 4.3$ & $14.3 \pm 2.3$ \\
\hline Postop. & $11.3 \pm 5.6$ & $11.9 \pm 5.8$ & $14.7 \pm 5.4^{*}$ \\
\hline \multicolumn{4}{|c|}{ 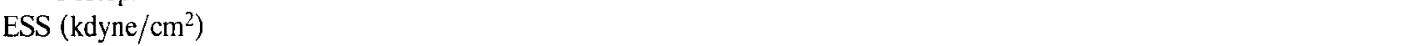 } \\
\hline Preop. & $246 \pm 80$ & $227 \pm 74$ & $217 \pm 63$ \\
\hline Postop. & $177 \pm 70$ & $191 \pm 47$ & $183 \pm 45$ \\
\hline \multicolumn{4}{|c|}{ ESS/ESVI $\left(\mathrm{kdyne} / \mathrm{cm}^{2} / \mathrm{ml} / \mathrm{m}^{2}\right)$} \\
\hline Preop. & $4685 \pm 1102$ & $4412 \pm 1369$ & $479 \pm 1564$ \\
\hline Postop. & $4787 \pm 827$ & $4526 \pm 1587$ & $4880 \pm 528$ \\
\hline
\end{tabular}

All numeric values are mean \pm standard deviation. $M V R$, Mitral valve replacement; $O M C$, open mitral commissurotomy; $C I$, cardiac index; $P C W$, Pulmonary capillary wedge pressure; $M V A$, mitral valve area; $E D V I$, end-diastolic volume index; $E S V I$, end-systolic volume index; $E F$, ejection fraction; $E S S$, end-systolic circumferential midwall stress.

${ }^{*} p<0.05$ (being compared with other groups).

$\dagger p<0.05$.

$\ddagger p<0.01$ (being compared with the preoperative values).

and volume data were not obtained simultaneously. The dicrotic notch pressures of five consecutive cardiac cycles were averaged and used to calculate end-systolic stress. End-systolic circumferential midwall stress was calculated from Mirsky's variation. ${ }^{7}$ Wall thickness was obtained by the method of Hugenholtz, Kaplan, and Hull. ${ }^{8}$ The ratio of end-systolic stress to end-systolic volume index, which is considered to be a load- independent index of LV contractility, was calculated by the method of Carabello, Nolan, and McGuire. ${ }^{9}$ Regional wall shortening of the $\mathrm{LV}$ was analyzed by the centerline method. ${ }^{10}$

The mean interval from operation to radionuclide study was $4.6 \pm 2.5$ years. MUGA was performed with the patient in the supine position. Studies were performed with red blood cells labeled with technetium $99 \mathrm{~m}$ and a 400ACT General Electric 
Table II. Echocardiography and multiple gated blood scintigraphy in the midterm postoperative periods

\begin{tabular}{|c|c|c|c|}
\hline & $\begin{array}{c}\text { Chordal preservation } \\
M V R \\
(\mathrm{n}=2 I)\end{array}$ & $\begin{array}{l}\text { Conventional MVR } \\
\qquad(\mathrm{n}=28)\end{array}$ & $\begin{array}{c}O M C \\
(\mathrm{n}=27)\end{array}$ \\
\hline \multicolumn{4}{|l|}{ Echocardiography } \\
\hline \multicolumn{4}{|l|}{ Dd } \\
\hline Preop. & $49.1 \pm 4.4$ & $47.7 \pm 3.6$ & $48.3 \pm 5.2$ \\
\hline Postop. & $50.4 \pm 5.7$ & $47.3 \pm 4.4$ & $47.9 \pm 44.0$ \\
\hline \multicolumn{4}{|l|}{ Ds } \\
\hline Preop. & $34.7 \pm 6.6$ & $33.6 \pm 4.2$ & $33.5 \pm 5.9$ \\
\hline Postop. & $33.3 \pm 6.8$ & $31.2 \pm 4.9$ & $31.9 \pm 5.4$ \\
\hline \multicolumn{4}{|l|}{ FS } \\
\hline Preop. & $0.30 \pm 0.09$ & $0.30 \pm 0.06$ & $0.31 \pm 0.08$ \\
\hline Postop. & $0.33 \pm 0.11$ & $0.34 \pm 0.07$ & $0.33 \pm 0.09$ \\
\hline \multicolumn{4}{|l|}{ MUGA (postop. data) } \\
\hline Ejection fraction & $0.54 \pm 0.12$ & $0.53 \pm 0.16$ & $0.56 \pm 0.09$ \\
\hline \multicolumn{4}{|l|}{ Radial shortenings } \\
\hline Anterobasal portion & $25.2 \pm 14.9$ & $28.6 \pm 9.2$ & $25.7 \pm 17.9$ \\
\hline Anterolateral portion & $32.1 \pm 26.5^{*}$ & $17.5 \pm 8.1$ & $27.8 \pm 15.6^{*}$ \\
\hline Basal septal portion & $5.8 \pm 8.5$ & $2.5 \pm 4.1$ & $9.8 \pm 11.5$ \\
\hline Apical septal portion & $12.7 \pm 5.1$ & $13.0 \pm 9.0$ & $17.3 \pm 13.1$ \\
\hline Inferoapical portion & $23.6 \pm 23.1$ & $26.8 \pm 9.0$ & $25.5 \pm 12.2$ \\
\hline Inferolateral portion & $44.5 \pm 11.1$ & $36.3 \pm 12.4$ & $33.5 \pm 13.3$ \\
\hline Posterolateral portion & $24.5 \pm 11.9$ & $20.0 \pm 15.5$ & $28.5 \pm 15.3$ \\
\hline
\end{tabular}

All numeric values are mean \pm standard deviation. $M V R$, Mitral valve replacement; $O M C$, open mitral commissurotomy; $D d$, diastolic dimension of the left ventricle; $D s$, systolic dimension of the left ventricle; $F S$, fractional shortenings; $M U G A$, Multiple-gated blood scintigraphy.

${ }^{*} p<0.05$.

Table III. Stress test: Exercise radionuclide ventriculography

\begin{tabular}{|c|c|c|c|c|}
\hline & Rest (before) & $25 \mathrm{~W}$ & $50 \mathrm{~W}$ & Rest (after) \\
\hline \multicolumn{5}{|c|}{ P-MVR $(n=12)$} \\
\hline $\mathrm{EF}(\%)$ & $53.2 \pm 12.4$ & $58.9 \pm 20.1$ & $64.0 \pm 18.6$ & $58.4 \pm 16.9$ \\
\hline DP & $9,540 \pm 1,100$ & $15,030 \pm 3,452$ & $16,160 \pm 4,010$ & $12,090 \pm 2,870$ \\
\hline \multicolumn{5}{|c|}{ C-MVR $(n=17)$} \\
\hline $\mathrm{EF}(\%)$ & $58.4 \pm 17.3$ & $62.7 \pm 21.4$ & $64.2 \pm 17.3$ & $61.3 \pm 13.2$ \\
\hline DP & $8,640 \pm 2,450$ & $13,730 \pm 2,230$ & $16,680 \pm 2,560$ & $11,480 \pm 1,980$ \\
\hline
\end{tabular}

All numeric values are mean \pm standard deviation. $P-M V R$, Chordal preservation mitral valve replacement; $C-M V R$, conventional mitral valve replacement; $E F$, ejection fraction; $D P$, double products (Systolic blood pressure [ $\mathrm{mm} \mathrm{Hg}$ ] $\times$ Heart rate [beats $/ \mathrm{min}]$ ).

Maxicamera (General Electric Company, Fairfield, Conn.) equipped with a collimator oriented in the modified left anterior oblique and anterior positions. In patients with atrial fibrillation, at least 500 beats with a cycle length approximating the average were chosen for analysis. The $L V$ ejection fraction was computed from the time-activity curves. Exercise study was performed with a bicycle ergometer in the supine position and the exercise load was increased by $25 \mathrm{~W}$ increments every 3 minutes until the development of limiting fatigue or dyspnea. The electrocardiographic findings, heart rate, and blood pressure (by cuff sphygmomanometry) were continuously monitored during exercise.

The mean interval from operation to M-mode echocardiography was $5.1 \pm 3.1$ years. A $2.5 \mathrm{mHz} \mathrm{M}$-mode echographic transducer was placed against the chest wall, and the LV enddiastolic and end-systolic diameters from the records of five consecutive cardiac cycles were averaged. The end-diastolic diameter was measured from the top of the $\mathbf{R}$ wave of the simultaneously recorded electrocardiogram. The end-systolic diameter was measured at the point where the opposing ventricular walls most closely approximated each other. LV fractional shortening was then calculated.

The significance of differences between variables was estimated by Student's $t$ test and analysis of variance with $p<0.05$ being taken to indicate a significant difference. Survival was calculated by the actuarial method.

\section{Results}

No deaths occurred in the early or late follow-up periods. Preoperative catheterization (Table I) revealed that the cardiac index and mitral valve area were greatest in the OMC group. Pulmonary capillary wedge pressure 


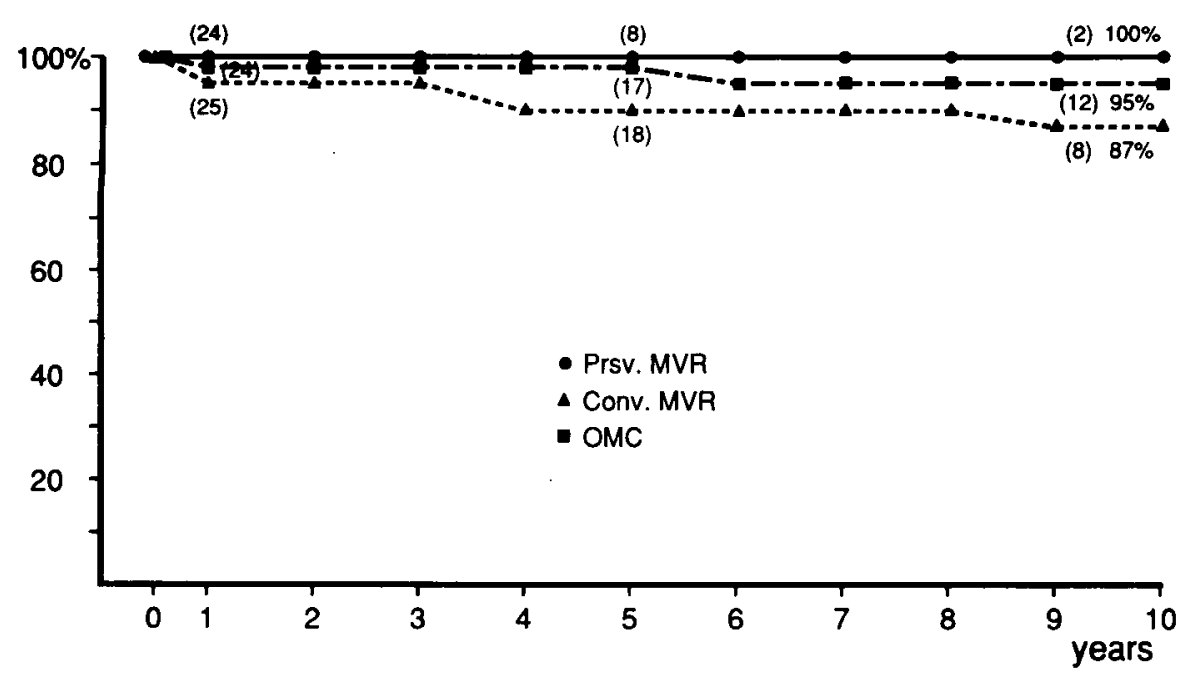

Fig. 2. Actuarial survival of the patients with mitral stenosis. Prsv. MVR, Chordal preservation mitral valve replacement; Conv. $M V R$, conventional MVR; OMC, open mitral commissurotomy. Numerals in parentheses are number of patients entered in analysis.

was highest in the conventional MVR group. The group showed no significant differences in other preoperative values, including regional shortening and echocardiographic and MUGA data. The postoperative cardiac index and mitral valve area were significantly increased and the pulmonary capillary wedge pressure decreased compared with the preoperative values in each group, but there were no significant differences among the three groups in postoperative cardiac index or mitral valve area. End-diastolic volume index and ejection fraction were somewhat increased after the operation, but these differences were not significant. End-systolic LV volume index and LV contractility index (end-systolic circumferential LV wall stress/end-systolic volume index) showed no significant change, but the postoperative LV ejection fraction in the chordal preservation group and the OMC group was greater than that in the conventional MVR group. Postoperatively, the regional shortening (Table I) was greatest at the diaphragmatic portion in the chordal preservation group and at the long-axis in the OMC group. None of the patients in the former group had a newly developed pressure gradient at the LV outflow tract after the operation.

In the mid-term postoperative period, although no differences were observed among the three groups in the echocardiographic data or global ejection fraction measured by the MUGA method, the regional shortening at the anterolateral portion of the LV in the chordal preservation group and in the OMC group was greater than that in the conventional MVR group (Table II). An exercise radionuclide angiography test (Table III) done with a bicycle ergometer failed to reveal any difference between the ejection fractions at rest, $25 \mathrm{~W}, 50 \mathrm{~W}$, and postexercise level in the chordal preservation group and the respective ejection fractions in the conventional MVR group. Also, no significant difference in pressure-rate product was noted at any exercise level between the two groups.

The most recent follow-up examination was conducted in August 1994, and no patients were lost to follow-up. The median and mean follow-up periods were 3.9 years and $3.2 \pm 5.8$ years, respectively, and the range was 0.2 to 9.7 years. The 5-year and 10-year survivals after chordal preservation MVR were both $100 \%$, with no significant difference between this group and the conventional and $\mathrm{OMC}$ groups (Fig. 2). There were no valve-related deaths or complications, such as valve failure, prosthetic endocarditis, thromboembolism, or bleeding. All of the patients who underwent chordal preservation MVR were reoperation free. This result was identical to that of the conventional MVR group but superior to that in the OMC group (69\% at 10 years) (Fig. 3).

\section{Discussion}

In 1956, Rushmer ${ }^{11}$ showed in canine experiments that the integrity of the mitral valve apparatus and its attachment to the ventricular wall play an important role in $\mathrm{LV}$ function. The importance of preservation of the native valve and the attached chordae in MVR was initially introduced by Lillehei, Levy, and Bonnabeau ${ }^{12}$ in 1964. However, Björk, Björk, and Malers ${ }^{13}$ and Rastelli and $\operatorname{Kirklin}^{14}$ refuted the potential beneficial effects of chor- 


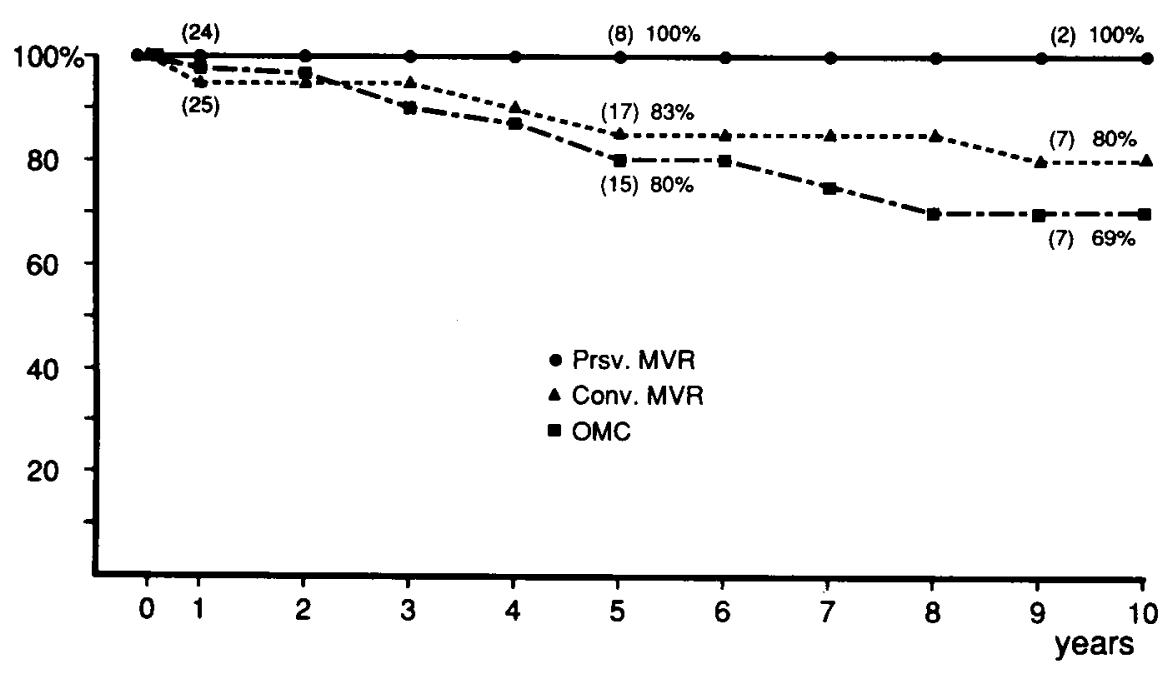

Fig. 3. Freedom from reoperation of patients with mitral stenosis. For abbreviations see Fig. 2.

da-sparing MVR, and it did not gain wide acceptance. In addition, high-profile mechanical prostheses were used almost exclusively at that time, and considerable concern was expressed that the residual chordae preserved by this technique might interfere with the movement of the poppet.

In canine experiments, Hansen, ${ }^{15}$ Yun, ${ }^{16}$ and their associates demonstrated that both global and regional $\mathrm{LV}$ systolic performance were impaired when the chordal attachments of the mitral valve were disrupted, and that dyskinesia developed at the site of papillary muscle insertion after the chordae were severed. Gams and associates ${ }^{17}$ reported increased $\mathrm{LV}$ dimension and impairment of the LV ejection performance after severance of the chordae tendineae of the canine mitral valve. Using porcine models, Sarris and associates ${ }^{18}$ confirmed that the acute decrease in LV contractility associated with surgical interruption of the annular-ventricular continuity could be reversed by reattachment of the chordae. Using canine models with chronic mitral regurgitation, Ishihara and associates ${ }^{19}$ recently found that not only depressed LV contractile function but also abnormal myocyte function of the LV returned to normal after MVR with chordal preservation. Rijk-Zwikker and associates ${ }^{20}$ reported that isolated porcine hearts into which a rigid mitral ring was implanted without valve replacement showed better contractile function than hearts into which a mechanical mitral prosthesis was implanted, because mitral annular-LV continuity was maintained in the former group.

The presentation of clinical reports by David, ${ }^{1}$ Spen$\mathrm{ce}^{21}$ and their associates and by Hetzer and colleagues ${ }^{2}$ in 1983 was followed by the reemergence of chordal preservation as an important method of maintaining LV function after MVR. Goor and coworkers ${ }^{22}$ reported that the postoperative survival of patients with ischemic mitral regurgitation was improved after MVR with chordal preservation compared with patients who underwent conventional MVR. We previously reported early ${ }^{5}$ and mid-term ${ }^{3}$ results after application of our chordal preservation technique for MVR using bileaflet prostheses. Hennein and associates ${ }^{23}$ reported a definite difference between the postoperative survival, exercise capacity, and LV function of patients who underwent MVR with chordal preservation and these parameters in those who underwent MVR by the conventional method. Recently, Rozich and associates ${ }^{24}$ reported the hemodynamic advantages of chordal preservation in MVR in patients with mitral regurgitation and compared the results of mitral valve repair with those of conventional MVR. ${ }^{25,26}$ The LV performance in the patients who underwent mitral valve repair and the actuarial analysis of long-term results indicated the improved survival and functional status in this group. Rozich and colleagues ${ }^{24}$ attributed the superiority of the repair technique to the restoration of near-normal valve function, the proper distribution of stress throughout the valve mechanism, and mitral anulus-LV continuity. ${ }^{25-27}$ Thus the hemodynamic advantages of maintaining the annulopapillary muscular continuity in MVR or of performing valve repair for patients with mitral regurgitation have been well documented, although no clinical investigation of postoperative LV performance has been conducted exclusively in patients with pure mitral stenosis who underwent chordal preservation MVR. David ${ }^{4}$ first reported the technique of reconstructing synthetic chordae after excision of the 
mitral apparatus, but the postoperative hemodynamic status of these patients was not described in detail.

The possibility of LV dysfunction in patients with mitral stenosis was raised by Harvey and associates, ${ }^{28}$ who suggested that some "myocardial factor" was one of the causes of impaired LV performance. The rigid subvalvular apparatus in mitral stenosis has been considered to be another cause of LV dysfunction. ${ }^{28,}{ }^{29}$ However, recent cardiomechanical studies ${ }^{30}$ have demonstrated that the LV contractility in mitral stenosis is normal and that reduced preload and increased afterload on the LV are the main sources of preoperative LV dysfunction. Gash and associates ${ }^{30}$ reported that the ratio of end-systolic stress to end-systolic volume index in mitral stenosis is normal. Postoperative or posttransvenous mitral commissurotomy investigations ${ }^{31}$ have revealed that improved cardiac performance can be attributed to increased preload on the $\mathrm{LV}$ and reduction of pulmonary arterial pressure. However, the chordal preservation group demonstrated no improvement over the conventional MVR group in postoperative hemodynamic parameters, especially LV contractility, in our study. Similarly, Schuler and coworkers ${ }^{32}$ reported that the postoperative end-diastolic dimension, end-systolic dimension, and ejection fraction did not change significantly until 15 months after the operation in patients with mitral stenosis, a clear contrast to results in patients with mitral regurgitation. Radionuclide angiography during exercise has been reported to provide significant and sensitive prognostic information regarding $L V$ function in patients with coronary arterial disease or valvular heart disease. ${ }^{33,34}$ In our study, the ejection fraction and the pressure-rate products, measured by MUGA with the use of a bicycle ergometer in the chordal preservation group, did not differ from those in the conventional MVR group, and the response of the $\mathrm{LV}$ motion to the exercise stress was similar in the two groups. We could not demonstrate any direct advantageous effect of chordal preservation MVR on global LV performance in patients with mitral stenosis, even though this effect has clearly been confirmed in patients with mitral regurgitation. ${ }^{3}$

Regarding the regional contraction of the LV, Heller and associates $^{29}$ showed that ejection fraction was decreased and systolic wall motion was impaired in the posterobasal area of the LV in patients with mitral stenosis. Curry, Elliot, and Ramsey ${ }^{35}$ reported that the systolic motion in patients with mitral stenosis was impaired at the anterolateral portion as well as the posterobasal portion. Autopsy studies by $\mathrm{Kirch}^{36}$ and Grant ${ }^{37}$ led them to postulate that in mitral stenosis the mitral valve ring, leaflets, chordae tendineae, and papillary muscles form a rigid complex that restricts the adjacent LV. Kazama and associates ${ }^{38}$ reported that the systolic wall motion at the posterobasal portion of the $\mathrm{LV}$ is improved after OMC in patients with mitral stenosis, whereas the regional motion of this portion is impaired after conventional MVR, in which the chordae tendineae are severed. Pitarys and associates $^{39}$ demonstrated that although the average radial shortening and $\mathrm{LV}$ ejection fraction were unchanged 10 years after conventional MVR, the radial shortening in the vicinity of the insertion of the posteromedial or anterolateral papillary muscles declined significantly. Our results also revealed that the postoperative regional motion at the diaphragmatic or anterolateral portions of the LV in patients who underwent chordal preservation MVR was greater than that in patients who underwent conventional MVR.

One of the technical difficulties in reconstruction with artificial chordae tendineae during MVR for patients with mitral stenosis is the determination and measurement of the length and direction of the new chordae. Although Frater ${ }^{40}$ described anatomic rules for determining this length, the distance between the tips of the papillary muscles and the mitral anulus varies according to size of the heart, anatomic variations or lesions of the papillary muscles, and technical modifications. Akins and associates ${ }^{41}$ described that the length of the subvalvular apparatus is directly related to the severity of the subvalvular fibrotic changes. We measured this distance at autopsy in 70 consecutive hearts from Japanese patients without cardiac disease. Accordingly, our reconstructed synthetic chordae range from 2.0 to $2.3 \mathrm{~cm}$ in length, because in patients with mitral stenosis the annulopapillary muscle distance is generally shorter than that in the normal heart and because the synthetic chordae should be taut to generate some tension.

With regard to the mechanical properties and durability of the implanted e-PTFE chordae, Cochran and Kunzelman $^{42}$ reported that the e-PTFE chordae tendineae exhibit some viscoelastic characteristics in experimental models. Vetter, ${ }^{43}$ Zussa, ${ }^{44}$ and their associates experimentally replaced the chordae of the anterior mitral leaflet with e-PTFE sutures and concluded that these sutures have a natural level of flexibility and are clinically durable for at least 4 years. David, Boss, and Rakowski ${ }^{45}$ reported that histologic sections of explanted e-PTFE chordae contained plasma proteins in their interstices but were not covered by cellular components. On the other hand, Revuelta and associates, ${ }^{46}$ using scanning and transmission electron microscopy in sheep, found that the e-PTFE suture was completely covered by a sheath of tissue with a collagen structure similar to that of a native chorda. We have noted no deleterious effect or chordal preservation-related complications of this technique at 
midterm follow-up, and we plan to continue to preserve or replace the chordae tendineae in patients with mitral stenosis unless this technique is demonstrated to be detrimental.

An additional role of the papillary muscles is a buttressing effect on the base of the heart as it contracts, thereby reducing the afterload stress on this region and improving minor-axis shortening. ${ }^{11}$ Although the most common contributing factors to posterior $\mathrm{LV}$ rupture are undue traction on the anulus, penetration of the stitches into the atrioventricular groove, or perforation of the ventricular wall as a papillary muscle is excised; the mechanism of the $\mathrm{LV}$ rupture at the midportion of the posterior wall is not certain. The results of investigations $\mathrm{s}^{47,48}$ into the cause of transverse midventricular disruption after MVR support this additional role of the papillary muscles. Thus detachment of the papillary muscles from the mitral anulus may transect this major vertical muscle fiber loop, increase longitudinal stress on the remaining endocardium, and allow the untethered ventricle to overexpand longitudinally. The result would be to markedly alter both regional wall stresses and systolic contractility, especially in mitral stenosis, in which the LV wall is usually thin. Spencer, Galloway, and Colvin $^{49}$ reported that midventricular disruption was less prevalent when the posterior leaflet chordae were preserved in MVR. We consider that preservation of the autologous chordae or reconstruction with e-PTFE chordae can generate a buttressing effect against the stretching force in the posterior ventricular wall.

Although our study was nonrandomized and retrospective, the 10-year survival in our patients after preservation MVR was $100 \%$, and all were free from reoperation at 10 years. Horstkotte and associates ${ }^{50}$ reported that the survival and event-free survival at 5 years after MVR with chordal preservation were significantly different from those with MVR without chordal preservation. However, more extensive and controlled studies with longer follow-up periods are necessary to clarify the complex effect of the reconstructed chordae tendineae on LV performance after MVR in patients with mitral stenosis.

\section{REFERENCES}

1. David TE, Uden DE, Strauss HD. The importance of the mitral apparatus in left ventricular function after correction of mitral regurgitation. Circulation 1983;68(Suppl):II7682.

2. Hetzer R, Bougioukas G, Franz M, Borst HG. Mitral valve replacement with preservation of papillary muscles and chordae tendineae: revival of a seemingly forgotten concept. Thorac Cardiovasc Surg 1983;31:291-6.

3. Okita Y, Miki S, Kusuhara K, et al. Analysis of left ven- tricular motion after mitral valve replacement with a technique of preservation of all chordae tendineae: comparison with conventional mitral valve replacement or mitral valve repair. J THORAC CARdiovasc Surg 1992;104:786-95.

4. David TE. Mitral valve replacement with preservation of chordae tendineae. Saudi Heart J 1990;1:32-6.

5. Miki S, Kusuhara K, Ueda Y, Komeda M, Okita Y, Tahata T. Mitral valve replacement with preservation of chordae tendineae and papillary muscles. Ann Thorac Surg 1988;45:28-34.

6. Okita Y, Miki S, Ueda Y, Tahata T, Sakai T, Matsuyama K. Replacement of chordae tendineae using expanded polytetrafluoroethylene (ePTFE) sutures during mitral valve replacement in patients with mitral stenosis. J Cardiac Surg 1993;8:567-78.

7. Mirsky I. Left ventricular stresses in the intact human heart. Biophys J 1969;9:189-208.

8. Hugenholtz PG, Kaplan E, Hull E. Determination of left ventricular wall thickness by angiography. Am Heart $\mathbf{J}$ 1969;78:513-22.

9. Carabello BA, Nolan SP, McGuire LB. Assessment of preoperative left ventricular function in patients with mitral regurgitation: value of the end-systolic wall stress-end-systolic volume ratio. Circulation 1981;64:1212-7.

10. Sheehan FH, Bolson EL, Dodge HT, Mathey DG, Schofer J, Woo HW. Advantages and applications of the centerline method for characterizing regional ventricular function. Circulation 1986;74:293-305.

11. Rushmer RF. Initial phase of ventricular systole: asynchronous contraction. Am J Physiol 1956;184:188-94.

12. Lillehei CW, Levy MJ, Bonnabeau RC Jr. Mitral valve replacement with preservation of papillary muscles and chordae tendineae. J THORAC CARDIOvASC SURG 1964; 47:532-43.

13. Björk VO, Björk, Malers E. Left ventricular function after resection of the papillary muscles with total mitral valve replacement. J THORAC CARDIOVASC SURG 1964;48:6359.

14. Rastelli GC, Kirklin JW. Hemodynamic state early after prosthetic replacement of mitral valve. Circulation 1966; $34: 448-61$.

15. Hansen DE, Cahill PD, Derby GC, Miller DC. Relative contributions of the anterior and posterior mitral chordae tendineae to canine global left ventricular systolic function. J Thorac Cardiovasc Surg 1987;93:45-55.

16. Yun KL, Fann JI, Rayhill SC, et al. Importance of the mitral subvalvular apparatus for left ventricular segmental mechanics. 1990;82(S-4):89-104.

17. Gams E, Hagl S, Schad H, Heimisch W, Mendler N, Sebening F. Importance of the mitral apparatus for left ventricular function: an experimental approach. Eur J Cardiothorac Surg 1992;6:S17-24.

18. Sarris GE, Cahill PD, Hansen DE, Derby GC, Miller DC. Restoration of left ventricular systolic performance after reattachment of the mitral chordae tendineae. J THORAC CARDIOVASC SURG 1988;95:969-79. 
19. Ishihara K, Zile MR, Kanazawa S, et al. Left ventricular mechanics and myocyte function after correction of experimental chronic mitral regurgitation by combined mitral valve replacement and preservation of the native mitral valve apparatus. Circulation 1992;86(Suppl):II16-25.

20. Rijk-Zwikker GL, Schipperheyn JJ, Huysmans HA, Bruschke AVG. Influence of mitral valve prosthesis or rigid mitral ring on left ventricular pump function. Circulation 1980;89(Suppl)I1-7.

21. Spence PA, Peniston CM, David TE, et al. Toward a better understanding of the etiology of left ventricular dysfunction after mitral valve replacement: an experimental study with possible clinical implications. Ann Thorac Surg 1986;41:363-71.

22. Goor DA, Mohr R, Lavee J, Serraf A, Smolinsky A. Preservation of the posterior leaflet during mechanical valve replacement for ischemic mitral regurgitation and complete myocardial revascularization. J THORAC CARDIOVASC SURG 1988;96:253-60.

23. Hennein HA, Swain JA, McIntosh CL, Bonow RO, Stone $\mathrm{CD}$, Clark RE. Comparative assessment of chordae preservation versus chordae resection during mitral valve replacement. J Thorac Cardiovasc Surg 1990;99:82837.

24. Rozich JD, Carabello BA, Usher BW, Kratz JM, Bell AE, Zile MR. Mitral valve replacement with and without chordae preservation in patients with chronic mitral regurgitation. Circulation 1992;86:1718-26.

25. Perier P, Deloche A, Chauvaud S, et al. Comparative evaluation of mitral valve repair and replacement with Starr, Björk, and porcine valve prostheses. Circulation 1984; 70(Suppl):I187-92.

26. Yacoub M, Halim M, Radley-Smith R, McKay R, Nijveld A, Tower M. Surgical treatment of mitral regurgitation caused by floppy valve: repair versus replacement. Circulation 1981;64(Suppl):II210-6.

27. Bonchek LI, Olinger GN, Siegel R, Tresch DD, Keelan $\mathrm{MH}$. Left ventricular performance after mitral reconstruction for mitral regurgitation. J THORAC CARDIOVASC SURG 1984;88:122-7.

28. Harvey RM, Ferrer MI, Samet P, et al. Mechanical and myocardial factors in rheumatic heart disease with mitral stenosis. Circulation 1955;11:531-51.

29. Heller SJ, Carleton RA. Abnormal left ventricular contraction in patients with mitral stenosis. Circulation 1940;42:1099-110.

30. Gash A, Carabello BA, Cepin D, Spamm JF. Left ventricular ejection performance and systolic muscle function in patients with mitral stenosis. Circulation 1983;67:148-54.

31. Goto S, Handa S, Akaishi M, Abe S, Ogawa S. Left ventricular ejection performance in mitral stenosis, and effects of successful percutaneous transvenous mitral commissurotomy. Am J Cardiol 1992;69:233-7.

32. Schuler G, Peterson KL, Johnson A, et al. Temporal .response of left ventricular performance to mitral valve surgery. Circulation 1979;59:1218-31.
33. Borer JS, Bachararach SL, Green MK, Kent KM, Epstein SE, Johnston GS. Real-time radionuclide cineangiography in the noninvasive evaluation of global and regional left ventricular function at rest and during exercise in patients with coronary-artery disease. N Engl J Med 1977;296:83944.

34. Bonow RO, Lakatos E, Maron BJ, Epstein SE. Serial long-term assessment of the natural history of asymptomatic patients with chronic aortic regurgitation and normal left ventricular systolic function. Circulation 1991;84:162535.

35. Curry GC, Elliot LP, Ramsey HW. Quantitative left ventricular angiographic findings in mitral stenosis. Am J Cardiol 1972;29:621-7.

36. Kirch E. Alterations in size and shape of individual regions of heart in valvular disease. Ver Deutsch Kong Inn Med 1929;41:324-36.

37. Grant RP. Architectonics of the heart. Am Heart J 1953;46:405-31.

38. Kazama S, Nishiguchi K, Sonoda K, et al. Postoperative left ventricular function in patients with mitral stenosis. Jpn Heart J 1986;27:35-42.

39. Pitarys CJ, Forman MB, Panayiotou H, Hansen DE. Long-term effects of the mitral apparatus on global and regional ventricular function in humans. J Am Coll Cardiol 1990;15:557-63.

40. Frater RWM. Anatomical rules for the plastic repair of a diseased mitral valve. Thorax 1964;12:458-64.

41. Akins CW, Kirklin JK, Block PC, Buckley MJ, Austen WG. Preoperative evaluation of subvalvular fibrosis in mitral stenosis: a predictive factor in congestive vs replacement surgical therapy. Circulation 1979;60(Suppl): 171-6.

42. Cochran RP, Kunzelman KS. Comparison of viscoelastic properties of suture versus porcine mitral valve chordae tendineae. J Cardiac Surg 1991;6:508-13.

43. Vetter HO, Burch JH, Factor SM, Macaluso F, Frater RWM. Replacement of chordae tendineae of the mitral valve using the new expanded PTFE sutures. In: Bodonar E, Yacoub M, eds. Biologic and bioprosthetic valves. Ist ed. New York: Yorke Medical Books, 1986:732-85.

44. Zussa C, Frater RW, Polesel E, Galloni M, Valfré C. Artificial mitral valve chordae: experimental and clinical experience. Ann Thorac Surg 1990;50:367-73.

45. David TE, Bos J, Rakowski H. Mitral valve repair by replacement of chordae tendineae with polytetrafluoroethylene sutures. J THORAC Cardiovasc Surg 1991; 101: 495-501.

46. Revuelta JM, Garcia-Rinaldi R, Gaite L, Val F, Garijo F. Generation of chordae tendineae with polytetrafluoroethylene stents: results of mitral valve chordal replacement in sheep. J THORAC CARdIOvasC Surg 1989;97:98-103.

47. Cobbs BW Jr, Hatcher CR Jr, Craver JM. Transverse midventricular disruption after mitral valve replacement. Am Heart J 1980;99:33-50.

48. Miller DW Jr, Johnson DD, Ivey TD. Does preservation of 
the posterior chordae tendineae enhance survival during mitral valve replacement? Ann Thorac Surg 1979;28: 22-7.

49. Spencer FC, Galloway AC, Colvin SB. A clinical evaluation of the hypothesis that rupture of the left ventricle following mitral valve replacement can be prevented by preservation of the chordae of the mural leaflet. Ann Surg 1985;202:673-80.

50. Horstkotte D, Schulte HD, Bircks W, Strauer BE. The effect of chordae preservation on late outcome after mitral valve replacement: a randomized study. J Heart Valve Dis 1993;2:150-8.

\section{Discussion}

Dr. Alain F. Carpentier (Paris, France). I rise to congratulate the authors and to express a note of caution. They have shown that preservation of chordae tendineae has a beneficial effect on LV function in mitral valve insufficiency but almost no effect in mitral valve stenosis. It would be dangerous to conclude from this study that preservation of chordae is not necessary in mitral valve stenosis. Besides improvement in ventricular function, there is another beneficial effect associated with the preservation of the mitral valve apparatus - the prevention of myocardial rupture. I would like the authors to confirm that they have not changed their policy with regard to the systematic preservation of chordae in mitral valve stenosis whenever a valve replacement is necessary.

Dr. Radu C. Deac (Tirgu-Mures, Romania). Is this a routine technique in every mitral stenosis case or only in a selected group? Did you identify any complication, early or late, of this technique, especially for the mitral stenosis group? Have you any explanation for the lack of major improvement in the mitral stenosis group? Finally, I think it would be appropriate to correlate the contractility data presented with the effective orifice area and gradient across the artificial valve implanted.

Dr. Christian E. Cabrol (Paris, France). Several times I have advocated before this Association the importance of the preservation of chordae tendineae in MVR. I will confirm what was said presently.

Not only does chordal preservation improve the preservation of LV function, but also it is the best way to prevent the rupture of the lateral wall of the $\mathrm{LV}$, especially in mitral stenosis. In mitral stenosis, chordae tendineae are retracted and protect the lateral wall. When the chordae are cut the lateral wall can be overstretched and in this condition can rupture. By the way, one of the best ways to cure such a lesion, with its tragic consequences, is to reconstruct the continuity between the papillary muscles and the anulus by suturing the papillary muscles to the anulus; it is sometimes the only possibility to save such patients with such severe lesions.

Dr. Roland Hetzer (Berlin, Germany). Since our first use of complete chordal preservation in MVR in 1980, this has become routine in Berlin during the recent 7 years in 1100 cases.

First, the traditional Lillehei posterior leaflet chordal preservation was applied. In the more recent 420 cases, complete chordal preservation was achieved by simply incising the commissures and the leaflets in the central radius. In one case the movement of one of the prosthetic leaflets was obstructed, but this was corrected during the same procedure.

When the effects of this technique were compared with those of a posterior leafiet preservation, transesophageal studies revealed superior function in the complete preservation cases. The difference was most prominent in longitudinal LV fractional shortening, in a positive pulmonary venous flow pattern, and in the patients having mitral stenosis.

I would like to ask Dr. Okita two questions: Have you seen any technical problems with the complete preservation group? How much emphasis would you place on the tension to which the anterior leaflet chordae should be subjected?

Dr. Robert W. M. Frater (Bronx, N.Y.). The question of mitral stenosis is of course the most interesting one. The normal connection between anulus and papillary muscle with a normal valve allows the posterior LV wall to elongate in diastole and shorten in systole. In rheumatic mitral stenosis this is a very unnatural connection and in fact forms a rigid bar, which almost certainly limits vasorelaxation and contraction. In your 20 patients with mitral stenosis you had 13 with PTFE chordae and 7 in whom you left the natural apparatus in place. Was ventricular function better in those 13 patients and did the other 7 benefit less overall?

Dr. Okita. Thank you all very much for the nice comments. They added very important information to a very difficult problems.

To answer Dr. Carpentier, we did not say it was unnecessary to preserve chordae in mitral stenosis. On the contrary, we are trying to preserve all the chordae in every patient with mitral stenosis.

To answer Dr. Deac, again, we are trying to preserve all the chordae tendineae in every patient with mitral stenosis. We had no complications with this technique. To answer your further question, there are no data to indicate an advantageous effect over mitral stenosis. If you analyze the postoperative LV performance in patients with mitral stenosis, you should change the preload or afterload to the LV, for example, by doing some exercise tests, during the postoperative catheterization. Now we are trying to do that.

I thank Dr. Cabrol for his nice comments. Dr. Hetzer, regarding the technical problem, we have had no difficulty in inserting the St. Jude Medical valve in bulky tissue, even in a rheumatic valve.

To answer Dr. Frater, we did analyze the 13 patients with mitral stenosis who had PTFE replacement versus the 7 patients with autologous chordal preservation. We could not find any difference in $L V$ performance at rest. We should do stress tests to evaluate $L V$ function. 